\title{
Avaliação hidrogeoquímica das águas superficiais e subterrâneas na região sudoeste da bacia do rio Subaúma, Bahia
}

\author{
Paulo Henrique Prado Stefano, \\ Sillas Alves de Cristo ${ }^{1}$ \\ Ivan Pastro Gomes' \\ Mirna Marierse Nepomuceno \\ Santos $^{3}$ \\ ${ }^{1}$ Departamento de Geologia \\ Universidade Federal de Sergipe \\ Av. Marechal Rondon Sn \\ São Cristovão SE Brasil \\ CEP 49100-000 \\ ${ }^{2}$ Programa de Pós-Graduação em Geociências \\ Universidade Federal do Rio Grande do Sul \\ Av. Bento Gonçalves 9500, \\ Porto Alegre RS Brasil \\ CEP 91501-570 \\ ${ }^{3}$ Departamento de Química \\ Universidade Federal de Sergipe \\ Av. Marechal Rondon Sn \\ São Cristovão SE Brasil \\ CEP 49100-000 \\ * Autor correspondente \\ paulohenriquestefano@hotmail.com
}

\section{RESUMO}

$\mathrm{O}$ presente estudo teve como objetivo avaliar as águas superficiais e subterrâneas da região sudoeste da bacia hidrográfica do Rio Subaúma, que compreende os municípios de Alagoinhas, Aramari e Inhambupe, BA. Foram amostrados 9 poços tubulares da região, entre eles poços residenciais e de localidades públicas como escolas e prédios da prefeitura. Além disso, foram analisadas 6 amostras de águas superficiais ao longo do rio, sendo que a primeira amostra foi coletada próxima a nascente e a última a jusante do povoado de Riacho da Guia. Foram analisados parâmetros como pH, cor, turbidez, ferro $(\mathrm{Fe})$, manganês $(\mathrm{Mn})$, amônia $\left(\mathrm{NH}_{3}\right)$, nitrato $\left(\mathrm{NO}_{3}-\right)$, nitrito $\left(\mathrm{NO}_{2}{ }^{-}\right)$, sólidos totais dissolvidos (STD), dureza, sódio $(\mathrm{Na})$, potássio $(\mathrm{K})$, magnésio $(\mathrm{Mg})$, cálcio $(\mathrm{Ca})$ fósforo $(\mathrm{P})$, fluoreto $\left(\mathrm{F}^{-}\right)$, sulfato $\left(\mathrm{SO}_{4}\right)$, cloreto $\left(\mathrm{Cl}^{-}\right)$, oxigênio dissolvido (OD), bicarbonato $\left(\mathrm{HCO}_{3}{ }^{-}\right)$e carbonato $\left(\mathrm{CO}_{3}{ }^{2-}\right)$. As águas subterrâneas foram classificadas em sua maioria como cloretadas sódica, com os íons $\mathrm{Na}$ e $\mathrm{Cl}$ em maior abundância. As águas superficiais mostraram uma significante contaminação antrópica a qual aumenta quanto mais a jusante na bacia hidrográfica. Os elevados teores de ferro tanto nas águas superficiais como nas águas subterrâneas foram atribuídos ao ferro contido na Formação Barreiras. Por fim, as águas da bacia podem ser utilizadas para fins de irrigação sem grandes restrições.

Palavras-chave: Hidrogeologia, Águas Superficiais, Águas subterrâneas, Análises físico-químicas

\section{ABSTRACT}

This study had as objective to evaluate groundwater and surficial water in Subaúma River Basin, which includes the cities of Alagoinhas, Aramari and Inhambupe, Bahia State. Nine tubular wells were selected in the region, including houses and public places such as schools and public buildings. In addition, six samples of surface waters were analyzed along the river, and the first one was collected close to the river source and the last one downstream from the village of Riacho da Guia. Parameters were analyzed as: $\mathrm{pH}$, color, turbidity, iron $(\mathrm{Fe})$, manganese $(\mathrm{Mn})$, ammonia $\left(\mathrm{NH}_{3}\right)$, nitrate $\left(\mathrm{NO}_{3}{ }^{-}\right)$, nitrite $\left(\mathrm{NO}_{2}{ }^{-}\right)$, total dissolved solids (STD), hardness, sodium $(\mathrm{Na})$, potassium $(\mathrm{K})$, magnesium $(\mathrm{Mg})$, calcium $(\mathrm{Ca})$, phospor $(\mathrm{P})$, fluoride $\left(\mathrm{F}^{-}\right)$, sulfate $\left(\mathrm{SO}_{4}\right)$, chloride $\left(\mathrm{Cl}^{-}\right)$, dissolved oxygen $(\mathrm{OD})$, bicarbonate $\left(\mathrm{HCO}_{3}{ }^{-}\right)$and carbonate $\left(\mathrm{CO}_{3}{ }^{2-}\right)$. The groundwater was classified mostly as sodium chlorate, with the $\mathrm{Na}$ and $\mathrm{Cl}$ ions with higher abundance. The surface waters showed a significant anthropic contamination, which increases downstream in the Basin. The high levels of iron in both surface water and groundwater were attributed to the iron contained in Formation Barreiras. Finally, the waters of the basin can be used for irrigation purposes without great restrictions.

Keywords: hydrogeology, Surface water, Groundwater, Physico-chemical Analysis 


\section{INTRODUÇÃO}

O estudo hidrogeológico de uma região, bem como o conhecimento da qualidade das águas de uma determinada localidade, é de extrema importância para o manejo e abastecimento da população. $\mathrm{O}$ aumento do uso das águas subterrâneas, muitas vezes realizado por poços sem os critérios técnicos corretos, bem como a contaminação das águas superficiais vem sendo um grande problema nas bacias hidrográficas brasileiras (Conicelli e Hirata, 2016).

No Brasil, a Portaria de Consolidação $N^{\circ} 5$ de 28 Setembro de 2017 do Ministério da Saúde dispõe sobre os procedimentos para controle e vigilância da qualidade das águas para consumo humano e seu padrão de potabilidade. Com isso, a norma estabelece os valores máximos permitidos de parâmetros físico-químicos, organolépticos e análises bacteriológicas para que uma água seja considerada potável. Além da portaria, a Resolução do Conselho de Meio Ambiente - CONAMA $\mathrm{N}^{\circ} 357$ de 2005, divide as águas em diversas classes a depender do seu uso. Dentre as inúmeras análises que podem ser realizadas para verificar a potabilidade de corpos d'água, tanto superficiais como subterrâneos, as análises físico-químicas e as análises de coliformes se tornam muito importantes, uma vez que indicam contaminação antrópica.

Os municípios de Alagoinhas, Inhambupe e Aramari - Bahia possuem, juntos, uma população de aproximadamente 170 mil Habitantes. (IBGE, 2010). Devido ao clima árido existente no Estado, a região sofre constantemente com falta de água superficial para o abastecimento público, tendo, portanto, um elevado número de poços tubulares na região, tanto para fins industriais como residencial.

A região sudoeste da bacia do Rio Subaúma (Figura 1), que tem uma população estimada em 10 mil habitantes, carece de estudos sobre a qualidade das águas superficiais. No curso de todo o rio, há residências isoladas e até mesmo povoados, como o de Riacho da Guia, os quais utilizam o corpo d'água para diversos fins.

Além da falta de conhecimento da qualidade das aguas superficiais, há poucos poços cadastrados com informações físico-químicas no Sistema de Informações de Águas Subterrâneas SIAGAS (CPRM, 2018) para os três municípios, sendo que apenas um desses poços encontra-se na área da bacia do Rio Subaúma, mostrando que muito pouco se sabe sobre as águas subterrâneas da área. Com isso, torna-se de extrema importância o conhecimento da qualidade das águas subterrâneas na região, uma vez que são amplamente utilizadas para irrigação, consumo próprio, entre outros.

Sendo assim, esse trabalho tem como objetivo avaliar a qualidade das águas superficiais e subterrâneas da região para fins tanto de potabilidade como para uso na agricultura, uma vez que a população local é dependente desse manancial hídrico.

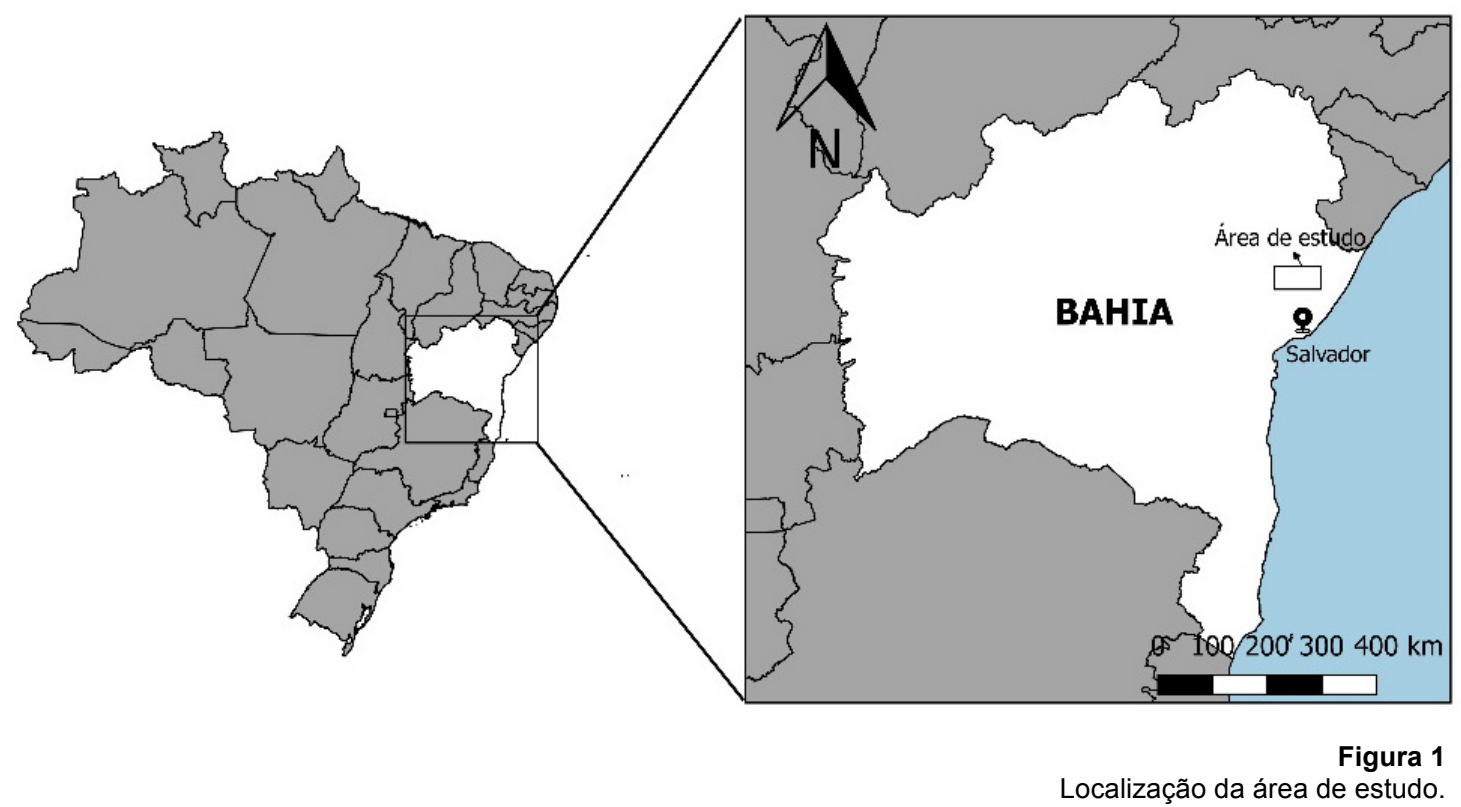




\section{GEOLOGIA E HIDROGEOLOGIA DA ÁREA DE ESTUDO}

A área desse projeto encontra-se na denominada Bacia do Recôncavo-Tucano Jatobá, a qual está situada na região nordeste do Brasil, leste do Estado da Bahia, compreendendo uma área de aproximadamente $11.000 \mathrm{~km}^{2}$. A bacia em questão é um exemplo das bacias brasileiras de rifte intracontinental abortado. $\mathrm{Na}$ parte pré rifte, a bacia é constituída pelos sedimentos do Grupo Brotas, os quais consistem em sedimentos aluviais, fluviais, eólicos e lacustres rasos. A seção rifte da bacia é marcada pelos sedimentos da Formação (Fm.) Salvador. A fase sin-rifte é mostrada pelos sedimentos das Formações Candeias e Ilhas, os quais consistem basicamente em folhelhos e arenitos turbiditicos. Por fim, a porção pré- rifte da bacia constitui a Formação Marizal e a Formação Barreiras (Milani, 2007). Na Área desse estudo, afloram as formações São Sebastião, Marizal e Barreiras (Figura 2).

A Fm. São Sebastião é composta por arenitos grossos a finos, de cor amarelo avermelhados, feldspáticos e com intercalações de argilas sílticas (Andrade et al, 2014). No setor basal, a formação possui arenitos finos a grossos, levemente calcíferos, feldspáticos, contendo nódulos de calcário castanho-avermelhado e intercalações delgadas de argila cinzaavermelhadas e avermelhadas. A parte mediana é composta por bancos espessos de arenitos cinza-amarelados a cinza-esbranquiçados, finos a médios, alternados por argilas sílticas e folhelhos sílticos. Já na parte superior, a formação é composta por arenitos cinzaavermelhados e vermelhos (Barbosa e Dominguez, 1996). O ambiente de deposição continental em que a Fm. São Sebastião está inserida sugere alternância com planície fluvial, planície deltaica e lagunar (Aboarrage, 1970).

A Fm. Marizal é constituída por arenitos, calcários, conglomerados e folhelhos. Sua deposição é atribuída a sistemas aluviais (sistemas fluviais e leques aluviais) na conjuntura de uma subsidência termal, pós-rifte, atestada pela sub-horizontalidade dos estratos (Andrade et al, 2014). Esta unidade sobrepõe os

\section{METODOLOGIA}

O estudo foi realizado com amostras de água superficial do Rio Subaúma e de poços tubulares sedimentos da Fm. São Sebastião, evidenciando uma discordância erosiva, composta por arenitos cinza-esbranquiçados a amarelados, de granulação fina a média e maciços. Englobam níveis de conglomerados na base, e intercalações de calcários, folhelhos e siltitos (Nascimento e Alves, 2014).

A Fm. Barreiras é desenvolvida por diamictitos amparados por lama, diamictitos sustentados por clastos, arenitos lamosos conglomeráticos, arenitos lamosos, arenitos lamosos conglomeráticos com estratificação cruzada e argilitos maciços. $\mathrm{O}$ ambiente deposicional associado à Fm. Barreiras é definido por leques aluviais compostos de arenitos fluviais grosseiros, médios e finos, cinza-esbranquiçados e amarelo-avermelhados, com baixa consolidação e níveis conglomeráticos nas seções basais. Esses arenitos compreendem estratificações cruzadas, podendo ocorrer também níveis com estratos plano-paralelos. A Fm. Barreiras dispõe-se, em discordância erosiva, sobre os sedimentos das formações Marizal, São Sebastião e entre outras unidades estratigráficas (Andrade et al, 2014).

O Sistema Aquífero Barreiras é formado por sedimentos sobrepostos a Fm. Marizal e a Fm. São Sebastião. Silveira Junior (2004) destaca que esse aquífero livre é muito importante pois funciona como área de recarga para os sistemas aquíferos sotopostos.

Nascimento et al (2014), mostram que as águas das três formações são predominantemente cloretadas sódicas. Os parâmetros bicarbonato, dureza total e ferro total são bem semelhantes para todas as formações. A salinidade expressa em Sólidos Totais Dissolvidos caracteriza as águas subterrâneas como de natureza doce. Tanto a Fm. Barreiras como a Fm. Marizal funcionam como área de armazenamento temporário para as águas que após essa passagem, são transportadas para o sistema aquífero São Sebastião. Portanto, não ocorre variação hidroquímica significativa entre as águas dos dois sistemas aquíferos, uma vez que os mesmos se conectam. 
Foram selecionados seis pontos de amostras de águas superficiais e nove de águas subterrâneas. As amostras subterrâneas foram coletadas a cerca de $2 \mathrm{Km}$ uma da outra ao longo da bacia do rio onde se concentra uma maior densidade populacional, formando uma malha linear de amostragem. Foi realizado o bombeamento dos poços por cerca de cinco minutos, visando a obtenção de dados representativos do aquífero a fim de minimizar a coleta de águas estacionárias. Os pontos de coletas superficiais abrangeram desde a nascente do rio Subaúma ( $\mathrm{S} 01)$ até o ponto de coleta a jusante do povoado de Riacho da Guia (S06).

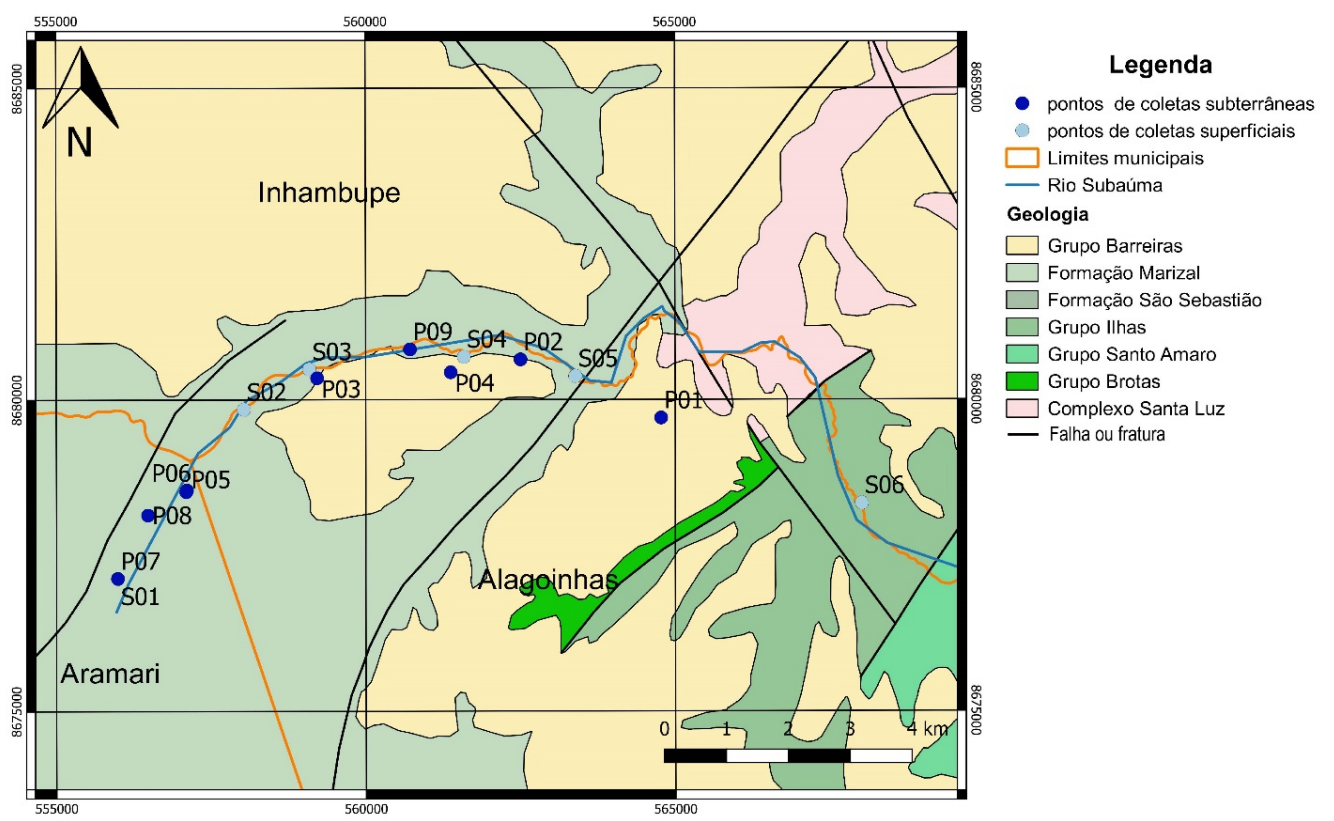

Figura 2

Mapa geológico da área de estudo e os pontos de coleta de amostras.

Para as análises e preservação das amostras de água, foram obedecidas as metodologias descritas no Standard Methods for Examination of Water and Wastewater (APHA, 2017). Foi possível avaliar os seguintes parâmetros físicoquímicos: $\mathrm{pH}$, cor, turbidez, ferro $(\mathrm{Fe})$, manganês $(\mathrm{Mn})$, amônia $\left(\mathrm{NH}_{3}\right)$, nitrato $\left(\mathrm{NO}_{3}-\right)$, nitrito $\left(\mathrm{NO}_{2}^{-}\right)$, sólidos totais dissolvidos (STD), dureza, sódio $(\mathrm{Na})$, potássio $(\mathrm{K})$, magnésio $(\mathrm{Mg})$, cálcio $(\mathrm{Ca})$ fósforo $(\mathrm{P})$, fluoreto $\left(\mathrm{F}^{-}\right)$, sulfato $\left(\mathrm{SO}_{4}\right)$, cloreto $\left(\mathrm{Cl}^{-}\right)$, oxigênio dissolvido (OD), bicarbonato $\left(\mathrm{HCO}_{3}^{-}\right)$e carbonato $\left(\mathrm{CO}_{3}{ }^{2-}\right)$.

As amostras foram coletadas em vasos de polietileno, isolados em uma caixa de isopor e armazenados em uma temperatura de aproximadamente $4^{\circ} \mathrm{C}$, até sua chegada ao laboratório.

As amostras para análise de coliformes termotolerantes foram armazenadas em um frasco de vidro previamente lavado e auto clavado, sendo realizadas em até 24 horas após as coletas. Em laboratório, foram submetidas a uma diluição seguida de filtração em membrana permeável, logo após inoculadas em meio de cultura apropriada e armazenadas em estufa a $45^{\circ} \mathrm{C}$, temperatura ideal para proliferação das bactérias.

Os resultados das análises experimentais foram colocados no programa Qualigraf, ferramenta que auxilia na parte gráfica das análises de águas, possibilitando determinar o índice de qualidade da água, classificar as amostras em relação aos sólidos totais dissolvidos e plotar os dados obtidos nos diagramas de Piper, risco de sódio e salinização do solo. Os resultados foram comparados com a Portaria de consolidação $\mathrm{N}^{\circ} 5 / 2017$ e a Resolução CONAMA N $\mathrm{N}^{\circ} 357 / 2005$, com o objetivo de verificar se os valores obtidos se encontram nos limites estabelecidos por estas resoluções 


\section{RESULTADOS E DISCUSSÕES}

\section{1. ÁGUAS SUPERFICIAIS}

A tabela 1 mostra os resultados dos parâmetros físico - químicos e microbiológicos das análises das águas do rio e seus respectivos valores máximos permitidos (VMP) em função do Conama $n^{\circ} 357$.

Tabela 1 - Resultados das análises de amostras superficiais e valores máximos permitidos pelo Conama.

\begin{tabular}{|c|c|c|c|c|c|c|c|}
\hline PARÂMETROS & VMP & S 01 & S 02 & S 03 & S 04 & S 05 & S 06 \\
\hline $\mathrm{pH}$ & $6-9$ & 5,2 & 5,4 & 5,5 & 5,1 & 5,4 & 6,3 \\
\hline $\mathrm{Cl}^{-}(\mathrm{mg} / \mathrm{L} \mathrm{Cl})$ & 250 & 20,52 & 16,14 & 22,96 & 19,56 & 15,29 & 56,59 \\
\hline $\mathrm{Fe}(\mathrm{mg} / \mathrm{L} \mathrm{Fe})$ & $\mathbf{0 , 3}$ & 0,3 & 0,4 & 0,6 & 0,1 & 0,3 & 0,6 \\
\hline $\mathrm{SO}_{4}{ }^{2-}\left(\mathrm{mg} / \mathrm{L} \mathrm{SO}_{4}\right)$ & 250 & 2,44 & 1,86 & 1,93 & 2,01 & 2,22 & 3,03 \\
\hline $\mathrm{NO}_{3}^{-}\left(\mathrm{mg} / \mathrm{L} \mathrm{NO}_{3}\right)$ & 10 & 0,1 & 0,1 & 0,1 & 0,1 & 0,1 & 0,1 \\
\hline $\mathrm{NO}_{2}^{-}\left(\mathrm{mg} / \mathrm{L} \quad \mathrm{NO}_{2}\right)$ & 1 & 0,05 & 0,05 & 0,05 & 0,34 & 0,05 & 2,29 \\
\hline $\mathbf{P}(\mathrm{mg} / \mathrm{L} \mathrm{P})$ & 0,1 & 0 & 0 & 0 & 0 & 0 & 0 \\
\hline Turbidez (NTU) & 40 & 1,1 & 2,5 & 7,2 & 4,8 & 4,1 & 3,2 \\
\hline STD $(\mathrm{mg} / \mathrm{L})$ & 500 & 76 & 42 & 54 & 44 & 44 & 144 \\
\hline$F^{-}(\mathrm{mg} / \mathrm{L} \mathrm{F})$ & 1,4 & 0,02 & 0,02 & 0,02 & 0,1 & 0,02 & 0,06 \\
\hline Mn (mg/L Mn) & 0,1 & 0 & 0 & 0 & 0 & 0 & 0 \\
\hline $\mathrm{OD}\left(\mathrm{mg} / \mathrm{L} \mathrm{O}_{2}\right)$ & $>6$ & 5,93 & 8 & 6,99 & 7,86 & 7,61 & 7,35 \\
\hline Coliformes (UFC) & _ & 55 & 90 & 285 & 355 & 295 & 3770 \\
\hline
\end{tabular}

Os valores de $\mathrm{pH}$ variaram entre 5,1 e 6,3 , sendo somente a amostra S06 enquadrada pelo Conama. Os baixos teores de $\mathrm{pH}$ em águas superficiais estão associados a concentração dos íons $\mathrm{H}^{+}$oriundos da dissociação do ácido carbônico. A presença desse ácido nos corpos d'água é resultante de fatores naturais como a solubilização do gás carbônico proveniente da atmosfera, chuvas e matéria orgânica que é consumida e oxidada na água, segundo Esteves (1988).

A presença de ferro em todas as amostras e acima do valor permitido nas superficiais 02,03 e 06, é resultante de altos teores de ferro proveniente da Fm. Barreiras, a qual apresenta crostas ferruginosas e óxidos de ferro (Correa, 2008).

O nitrogênio é um indicador de poluição por matéria orgânica, esgotos domésticos, despejos industriais e fertilizantes. Altos teores de nitrito (uma das formas oxidadas de nitrogênio) na amostra S06, caracterizam uma contaminação antrópica.

\section{2. ÁGUAS SUBTERRÂNEAS}

A tabela 2 mostra os resultados dos parâmetros físico - químicos e microbiológicos das análises das águas subterrâneas e seus
A análise microbiológica possibilitou indicar a presença dos coliformes fecais em todas as amostras. Nota-se que ocorre um aumento significativo na quantidade de coliformes a medida que se aproxima das regiões com maior densidade populacional, principalmente no ponto S06, a jusante do povoado de Riacho da Guia. A contaminação observada no ponto de coleta próximo a nascente pode estar associada a contaminação por meio de fossas irregulares e dejetos de animais conforme Bertoncini (2008). Os maiores valores próximos a áreas habitacionais evidenciam a provável contaminação antrópica por esgotos domésticos sem devido tratamento.

Sabendo que esta água é utilizada para abastecimento humano na região, tanto para consumo, como para irrigação de hortaliças e frutas que são consumidas cruas, necessita de tratamento simplificado. As águas da região se enquadram de acordo com a resolução Conama $\mathrm{n}^{\circ} 357$ como água doce classe I. 
Tabela 2 - Resultados das análises de amostras de águas subterrâneas e valores máximos permitidos.

\begin{tabular}{|c|c|c|c|c|c|c|c|c|c|c|}
\hline PARÂMETROS & VMP & P 01 & P 02 & P 03 & P 04 & P 05 & P 06 & P 07 & P 08 & P 09 \\
\hline Cor $(\mathrm{UH})$ & 15 & 2 & 0,6 & 4,5 & 2 & 0,7 & 80 & 4,5 & 11,8 & 3,4 \\
\hline Turbidez (UT) & 5 & 0,3 & 0,2 & 1,8 & 1,1 & 0,5 & 128 & 3,6 & 5,9 & 3 \\
\hline pH & $6-9$ & 6,7 & 6,3 & 4,6 & 5 & 4,5 & 5,1 & 4,8 & 6,8 & 4,7 \\
\hline $\operatorname{STD}(\mathrm{mg} / \mathrm{L})$ & 1000 & 322 & 68 & 38 & 124 & 48 & 28 & 26 & 32 & 316 \\
\hline Dureza $\left(\mathrm{mg} / \mathrm{L} \mathrm{CaCO}_{3}\right)$ & 500 & 178,34 & 8,88 & 13,26 & 17,44 & 12,17 & 16,66 & 11,02 & 13,91 & 51,09 \\
\hline $\mathrm{NH}_{3}(\mathrm{mg} / \mathrm{L} \mathrm{NH})$ & 1,5 & 0,05 & 0,05 & 0,05 & 0,05 & 0,05 & 0,05 & 0,05 & 0,05 & 0,05 \\
\hline $\mathrm{NO}_{2}^{-}\left(\mathrm{mg} / \mathrm{L} \mathrm{NO}_{2}^{-}\right)$ & 1 & 2,42 & 0,05 & 0,05 & 0,05 & 0,05 & 0,05 & 0,05 & 0,05 & 0,05 \\
\hline $\mathrm{NO}_{3}\left(\mathrm{mg} / \mathrm{L} \mathrm{NO}_{3}^{-}\right)$ & 10 & 21,81 & 0,69 & 2,5 & 4,77 & 0,85 & 0,47 & $<0,20$ & 0,21 & 37,39 \\
\hline $\mathrm{Na}\left(\mathrm{mg} / \mathrm{L} \mathrm{Na}^{+}\right)$ & 200 & 50,79 & 14,34 & 22,86 & 35,76 & 12,06 & 7,93 & 8,1 & 8,87 & 65,65 \\
\hline $\mathrm{Fe}(\mathrm{mg} / \mathrm{L} \mathrm{Fe})$ & 0,3 & 0 & 0 & 0,8 & 0,2 & 0,1 & 3,1 & 0,1 & 0,5 & 0,3 \\
\hline $\mathrm{SO}_{4}{ }^{2-}\left(\mathrm{mg} / \mathrm{L} \mathrm{SO}_{4}\right)$ & 250 & 5,38 & 2,06 & 1,29 & 0,94 & 5,92 & 2,06 & 1,38 & 1,77 & 4,67 \\
\hline $\mathrm{Cl}^{-}\left(\mathrm{mg} / \mathrm{L} \mathrm{Cl}^{-}\right)$ & 250 & 99,4 & 17,93 & 34,72 & 54,08 & 14,1 & 7,32 & 10,15 & 7,13 & 98,33 \\
\hline$P(\mathrm{mg} / \mathrm{L} \mathrm{P})$ & - & 3,86 & 0 & 0 & 0 & 0 & 0 & 0 & 0 & 0 \\
\hline $\mathrm{Ca}\left(\mathrm{mg} / \mathrm{L} \mathrm{Ca}{ }^{2+}\right)$ & - & 26,57 & 0,69 & 0,43 & 0,81 & 0,17 & 1,19 & 0,58 & 1,02 & 0,17 \\
\hline $\operatorname{Mg}\left(\mathrm{mg} / \mathrm{L} \mathrm{Mg}^{2+}\right)$ & - & 26,86 & 1,72 & 2,92 & 3,7 & 2,79 & 3,28 & 2,29 & 2,73 & 12,16 \\
\hline $\mathbf{K}\left(\mathbf{m g} / \mathbf{L ~} \mathbf{K}^{+}\right)$ & - & 2.01 & 6,4 & 0,66 & 2,34 & 0,21 & 2,89 & 0,32 & 5,23 & 0,69 \\
\hline $\mathrm{HCO}_{3}^{-}\left(\mathrm{mg} / \mathrm{L} \mathrm{HCO}_{3}{ }^{-}\right)$ & - & 111,23 & 0 & 10,67 & 13,06 & 0 & 0 & 0 & 0 & 17,03 \\
\hline $\mathrm{CO}_{3}{ }^{2-}\left(\mathrm{mg} / \mathrm{L} \mathrm{CO}_{3}{ }^{2-}\right)$ & - & 67,11 & 8,88 & 2,59 & 4,38 & 12,17 & 12,66 & 11,02 & 13,91 & 34,05 \\
\hline
\end{tabular}

$\mathrm{O}$ poço $\mathrm{P} 01$, localizado em uma propriedade rural onde há criação de animais além de plantações, apresentou teores elevados de $\mathrm{NO}_{3}{ }^{-} \mathrm{e}$ $\mathrm{NO}_{2}{ }^{-}$. Nesse caso, provavelmente os resíduos dos animais estão sendo incorporados pelo aquífero e contaminando as águas subterrâneas. $\mathrm{O}$ elevado teor de $\mathrm{NO}_{2}^{-}$ainda indica uma contaminação recente ocorrendo na localidade do poço. O elevado teor de fósforo também apresentado no poço tubular P01 é muito provavelmente oriundo de contaminação antrópica.

Quanto à cor e turbidez, o único poço que está fora do VMP é o P06, que apresenta índice de cor $80 \mathrm{UH}$ e turbidez $128 \mathrm{UT}$. Esse poço provavelmente mostra essas alterações devido a problemas de manutenção, que foram observados em campo.

Utilizando os diagramas de Piper (1944) com o programa Qualigraf, as águas subterrâneas da região de estudo foram classificadas preferencialmente como cloretadas sódicas, com algumas amostras caindo no campo das bicarbonatadas sódicas (Figura 3).

Tanto na formação barreiras como na formação Manguezal, ocorre a predominância do íon cloreto, seguido de $\mathrm{SO}_{4}$ e $\mathrm{HCO}_{3}{ }^{-}$
$\left(\mathrm{Cl}>\mathrm{SO}_{4}>\mathrm{HCO}_{3}{ }^{-}\right)$. Quanto aos principais cátions, o sódio aparece em maiores concentrações, seguido de magnésio e cálcio (Tabela 3). A elevada concentração dos íons $\mathrm{Na}^{+} \mathrm{e} \mathrm{cl}^{-}$nas águas da região se devem basicamente pela ação de águas meteóricas que infiltram tanto nas rochas da Fm. Barreiras quanto nas rochas da Fm. Marizal, ambas caracterizadas como aquíferos livres. Por ser uma área relativamente próxima ao litoral, esses ânions são carregados até a região, precipitando no local.

Percebe-se também que não há variação significativa da assinatura hidroquímica das águas extraídas diretamente do Sistema Aquífero Barreiras nem das águas do Sistema Aquífero Marizal, uma vez que, por se tratar de aquíferos livres, as águas subterrâneas tendem a se interconectar.

Em alguns dos poços tubulares ocorrem concentrações relativamente elevadas de ferro. Esse elemento provavelmente está associado a Fm. Barreiras, conforme nascimento et al (2014) que atribuiu as elevadas concentrações de ferro nas águas subterrâneas dos aquíferos oriundos dessa formação na região da bacia recôncavo norte á lixiviação dessa litologia.

\subsection{CLASSIFICAÇÃO DAS ÁGUAS DA BACIA DO RIO SUBAÚMA PARA FINS DE IRRIGAÇÃO}

As águas da bacia, tanto superficiais como subterrâneas, são muito utilizadas para fins de irrigação, uma vez que a região é produtora de hortaliças, laranja, milho, feijão mandioca, entre 
outros. A classificação das águas para fins de irrigação foi feita baseada na classificação do United States Salinity Laboratory - USSL, que utiliza a Razão de Adsorção de Sódio (RAS), mostrando o perigo de Sodificação das Águas (S) e a Condutividade Elétrica das Águas (CE), que interfere no perigo de Salinização (C).
Quanto a salinidade, as águas são classificadas em 5 categorias, $\mathrm{C} 0-\mathrm{C} 5$, onde $\mathrm{C} 0$ indica águas de muito baixa salinidade e C5 águas com salinidade extremamente elevada. Nessa mesma classificação também é utilizado o parâmetro $S$, de S1-S4, onde S1 são águas com baixo sódio e S4 águas com teores muito elevados de sódio.

Tabela 3 - Relação dos principais íons das águas subterrâneas da região de estudo.

\begin{tabular}{cll}
\hline AMOSTRA & CÁTIONS & \multicolumn{1}{c}{$\hat{\mathbf{A N I O N S}}$} \\
\hline P1 & $\mathrm{Na}>\mathrm{Ca}>\mathrm{Mg}$ & $\mathrm{Cl}>\mathrm{HCO}_{3}>\mathrm{SO}_{4}$ \\
P2 & $\mathrm{Na}>\mathrm{Mg}>\mathrm{Ca}$ & $\mathrm{Cl}>\mathrm{SO}_{4}>\mathrm{HCO}_{3}{ }^{-}$ \\
P3 & $\mathrm{Na}>\mathrm{Mg}>\mathrm{Ca}$ & $\mathrm{Cl}>\mathrm{HCO}_{3}>\mathrm{SO}_{4}$ \\
P5 & $\mathrm{Na}>\mathrm{Mg}>\mathrm{Ca}$ & $\mathrm{Cl}>\mathrm{HCO}_{3}>\mathrm{SO}_{4}$ \\
P6 & $\mathrm{Na}>\mathrm{Mg}>\mathrm{Ca}$ & $\mathrm{Cl}>\mathrm{SO}_{4}>\mathrm{HCO}_{3}{ }^{-}$ \\
P7 & $\mathrm{Na}>\mathrm{Mg}>\mathrm{Ca}$ & $\mathrm{Cl}>\mathrm{SO}_{4}>\mathrm{HCO}_{3}^{-}$ \\
P8 & $\mathrm{Na}>\mathrm{Mg}>\mathrm{Ca}$ & $\mathrm{Cl}>\mathrm{SO}_{4}>\mathrm{HCO}_{3}{ }^{-}$ \\
P9 & $\mathrm{Na}>\mathrm{Mg}>\mathrm{Ca}$ & $\mathrm{Cl}>\mathrm{SO}_{4}>\mathrm{HCO}_{3}^{-}$ \\
\hline
\end{tabular}

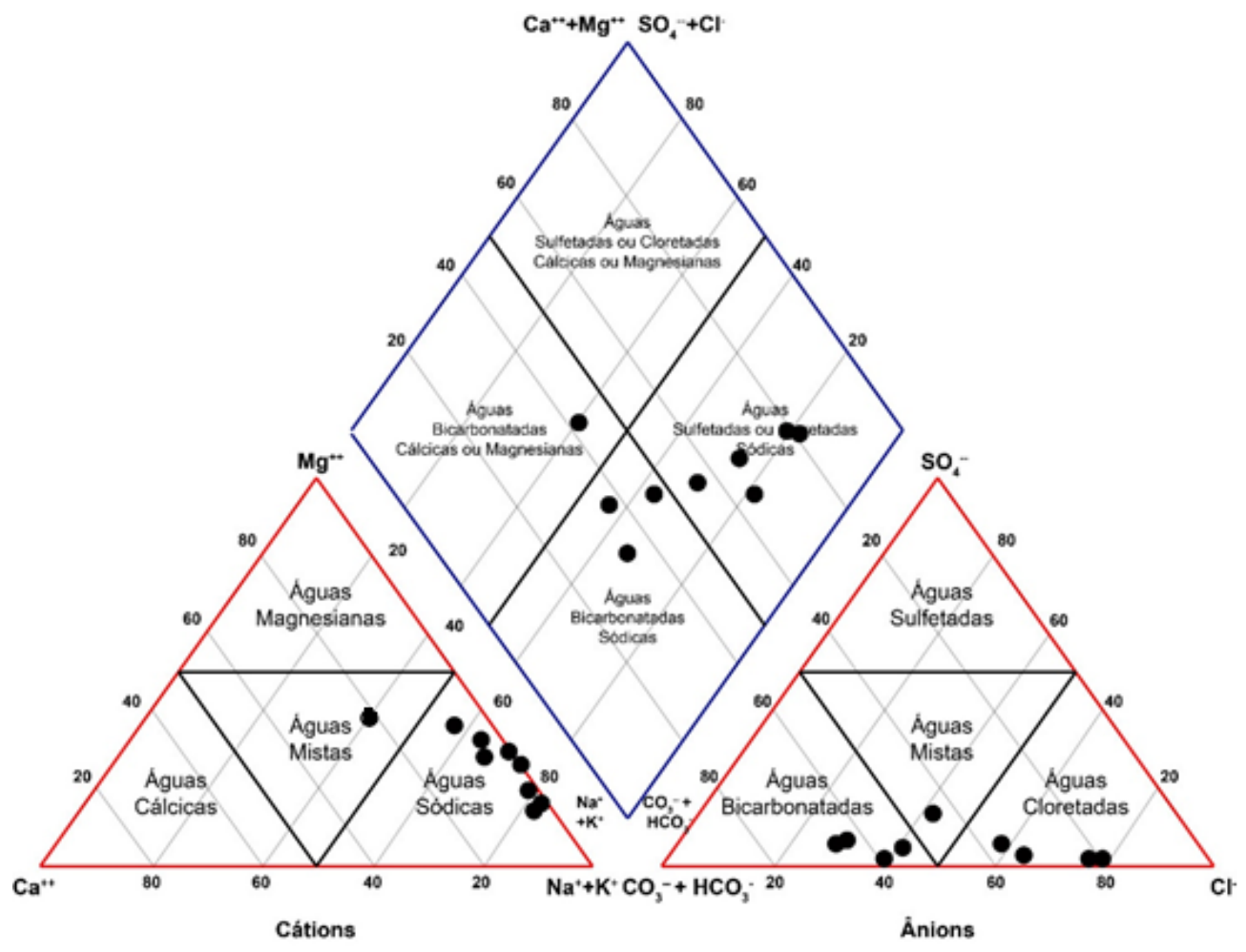

Figura 3

Classificação das águas subterrâneas baseadas no diagrama de Piper.

Das 15 amostras de águas, nove foram classificadas como $\mathrm{C} 0$-S1, águas com baixa salinidade e baixo teor de sódio, podendo ser utilizadas basicamente para todos tipos de cultivo. Essas amostras não aparecem no gráfico proposto pela USSL, uma vez que são considerados como risco nulo. Quatro amostras foram classificadas como $\mathrm{C} 1-\mathrm{S} 1$ e apenas duas amostras como C2-S1 (Figura 4). Águas C2, de salinidade média, devem ser utilizadas com precaução, sendo mais indicadas para solos arenosos e siltito-arenosos, como os solos oriundos das Fm. Barreiras e Marizal, encontrados na área de estudo. 


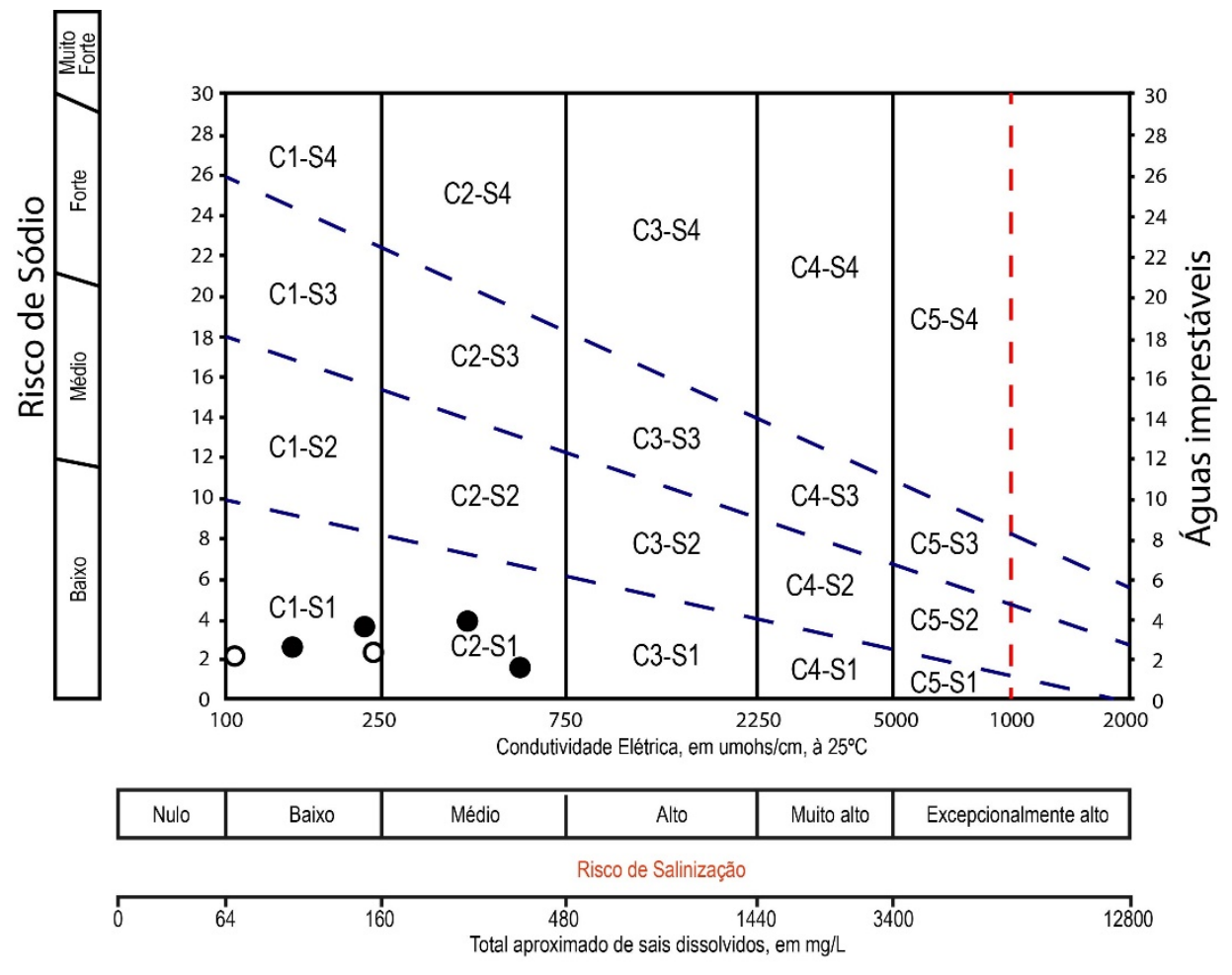

Legenda

- Amostras superficiais

- Amostras subterrâneas

Figura 4

Classificação das águas para fins de irrigação.

\section{CONCLUSÕES}

Baseado nas análises físico-químicas dás aguas subterrâneas, foi possível observar que os principais íons presentes nas águas são $\mathrm{Na}^{+} \mathrm{e} \mathrm{Cl}^{-}$ - Esse dado mostra que água meteórica está penetrando no aquífero livre. Baseado em diagramas de Piper, as águas são, em sua maioria, classificadas como cloretadas sódicas. Quanto a classificação das águas para irrigação, nota-se que as águas tanto superficiais como

\section{REFERÊNCIAS BIBLIOGRÁFICAS}

Aboarrage, A. M. Estudo da unidade cronoestratigráfica L-1 (Bacia do Recôncavo Formação São Sebastião). Rio de Janeiro: Petrobras, RPBA, Arquivo DIREX, 1970. (Relatório n. 1358).

Andrade, J. J. de S.; Nunes, F. C.; Vilas Boas, G. da S.; de-Carvalho, C. C. N. ; da-Silva, E. F "Estudo morfológico e morfométrico nas bacias do Riacho Cabuçu e Riacho dos Negros, litoral norte da subterrâneas da bacia podem ser utilizadas sem riscos para os cultivos realizados na região. As águas superficiais apresentam indícios de contaminação desde a área próxima a nascente, até a área do povoado de riacho da guia, onde os níveis de contaminação, principalmente de coliformes, aumentam significativamente. As águas superficiais podem ser classificadas como doce classe I.
Bahia." Embrapa Solos-Boletim de Pesquisa e Desenvolvimento (INFOTECA-E). 2014. http://www.infoteca.cnptia.embrapa.br/handle/doc 1995028

APHA. Standard Methods for Examination of Water and Wastewater. American Public Health Association, 23rd, Washington, DC. 2017

Bertoncini, E. I. Tratamento de efluentes e reúso da água no meio agrícola. Revista Tecnologia \& 
Inovação Agropecuária. v. 1, n. 1, p. 152-169, 2008.

Barbosa, J. S. F.; Dominguez, J. M. L. (Coord.). Geologia da Bahia: texto explicativo para o mapa geológico ao milionésimo. Salvador: Secretaria da Indústria, Comércio e Mineração. Superintendência de Geologia e Recursos Minerais, 1996. 400 p. Edição especial.

BRASIL. Portaria MS no 2914, de 12 de dezembro de 2011. Dispõe sobre os procedimentos de controle e de vigilância da qualidade da água para consumo humano e seu padrão de potabilidade. Diário Oficial da União, Brasília, 2011a. Disponível em: http://bvsms.saude.gov.br/bvs/saudelegis/gm/201 1/prt2 914_12_12_2011.html. Acesso em: 20 de junho de 2018.

Conicelli, B..P.; Hirata, R. Novos Paradigmas na Gestão nas Águas Subterrâneas. 2016. XIX Congresso Brasileiro de Águas Subterrâneas. Campinas SP 2016. Disponível em: https://aguassubterraneas.abas.org/asubterraneas/a rticle/view/28712

Correa, M. M.; Ker, J. C.; Barrón, V.; Fontes, M. P. F.; Torrent, J.; Curi, N. Caracterização de óxidos de ferro de solos do ambiente tabuleiros costeiros. Revista Brasileira de Ciência do Solo, 32(3), 121-131, 2008.
CPRM-Serviço Geológico do Brasil. Sistema de Informação de águas subterrâneas-SIAGAS. 2006. Acesso em Julho de 2018.

Esteves, F. A. "Fundamentos de Limnologia.". Interciência/Finep, 1988.

INSTITUTO BRASILEIRO DE GEOGRAFIA E ESTATÍSTICA. Indicadores de desenvolvimento sustentável: Brasil 2010. IBGE, 2010.

Milani, E. J., Rangel, H. D., Bueno, G. V., Stica, J. M., Winter, W. R., Caixeta, J. M., \& Neto, O. P. Bacias sedimentares brasileiras: cartas estratigráficas. Anexo ao Boletim de Geociências da Petrobrás, v. 15, n. 1, 2007.

Nascimento, S. A. M.; Alves, J. E. Estudo Hidrogeoquímico Comparativo Entre Os Aquíferos Barreiras, Marizal E São Sebastião Na Região Do Recôncavo Norte-Estado Da Bahia. Cadernos de Geociências, v. 11, n. 1-2, p. 72-82, 2014.

Piper, A. M. A Graphic Procedure in the Geochemical Interpretation of Water Anallysis. Transactions American Geophysical Union, Washington, v. 25, p. 911-923, 1944

Silveira Júnior, J. S. C. Avaliação do grau de internalização da proteção da água subterrânea no Pólo Industrial de Camaçari. Dissertação de mestrado Dissertação, Universidade Federal da Bahia, 111p. 2004. 